\title{
A política africana do governo Lula (2003-2006)
}

Cláudio Oliveira Ribeiro

Introdução

Em que pese a apreensão de vários setores políticos e econômicos (tanto em plano doméstico como externo), a eleição de Luiz Inácio Lula da Silva para a Presidência da República não chegou a alterar de forma substantiva a condução da política macroeconômica brasileira (cf. Paulani, 2003). O governo Lula manteve os parâmetros econômicos da gestão Fernando Henrique Cardoso (FHC) - o câmbio flexível associado a uma crescente abertura financeira; um regime de metas de inflação; e a realização de expressivos superávits primários nas contas públicas. $\mathrm{O}$ argumento governamental para a sustentação desse "tripé" é o de que somente a manutenção dos fundamentos de política macroeconômica seria capaz de garantir a "credibilidade" do governo junto aos mercados financeiros. O que, ademais, imporia o esforço de se criar condiçōes estruturalmente estáveis de financiamento do setor público, em especial, e pela via de reformas constitucionais (previdenciária, tributária, independência do Banco Central etc.), capazes de comprimir gastos e cristalizar o referido "tripé" (cf. Prates e Cunha, 2004).

Por outro lado, o curso da política externa brasileira sofreu consideráveis ajustes de agenda, sobretudo quando em comparação com o governo FHC, que teve como preocupação e meta externa a consolidação das relações com a corrente principal da economia global - Estados Unidos, Euro- 
1. Apesar da denominação, $o$ G-20 inclui formalmente 23 países, todos com bases industriais. São eles: África do Sul, Argentina, Bolívia, Brasil, Chile, China, Filipinas, Cuba, Egito, Equador, Guatemala, Índia, Indonésia, México, Nigéria, Paquistão, Paraguai, Peru, Tailândia, Tanzânia, Uruguai, Venezuela e Zimbábue. pa e Japão - em oposição às orientações terceiro-mundistas. Contando com Celso Amorim, reconduzido ao cargo de ministro das Relações Exteriores, o qual havia ocupado durante a gestão Itamar Franco, e com Marco Aurélio Garcia como assessor especial da Presidência da República para Assuntos Internacionais, o governo Lula promoveu mudanças significativas na política externa do país.

A agenda externa do governo seguiria no sentido do favorecimento da integração com a Argentina e a consolidação da Comunidade Sul-Americana de Nações (CASA); a promoção das exportações e a articulação de interesses com o G-201 nas negociaçōes da Organização Mundial do Comércio (OMC); o fortalecimento do multilateralismo, com a reforma da Organização das Nações Unidas (ONU) e do Conselho de Segurança; o aprofundamento da parceria com a Índia e a África do Sul; a aproximação com outras regiôes do mundo em desenvolvimento, como a África, os países árabes e a América Central e Caribe, e o desenvolvimento das relações com parceiros tradicionais (Estados Unidos, Europa, Japão), além de China e Rússia.

Como observa Lima (2003, p. 5), tais mudanças derivam do projeto internacional do governo, respaldado por sua visão do ordenamento internacional, ou seja, de que, no plano global, existe espaço para uma presença mais afirmativa do Brasil, o que reflete "uma certa avaliação da conjuntura mundial, que assume a existência de brechas para uma potência média como o Brasil, que, por via de uma diplomacia ativa e consistente, podem até ser ampliadas”. Tal percepção sobre a ordem internacional pode ser observada tanto nos pronunciamentos como nas iniciativas do governo Lula. É basicamente endossada pela avaliação de que, a despeito do predomínio militar logrado pelos Estados Unidos no plano global, a ordem econômica ainda guarda possibilidades mais pluralistas, pois, com a criação do euro, a União Europeia e sua moeda se fortalecem e, consequentemente, o poder do dólar enfraquece.

Portanto, constata-se a existência de um mundo menos homogêneo e mais competitivo, no qual, como considera o atual governo, haveria espaço para um movimento contra-hegemônico, cujos eixos estariam na Europa ampliada, com a inclusão da Rússia, e na Ásia, onde potências como China e Índia podem vir a representar um contraponto aos Estados Unidos na região. Por essa percepção, "a unipolaridade não consegue se legitimar, pois a tentação imperial é permanente, e isso, simultaneamente, estimula o investimento das demais potências" (Lima, 2003, p. 5). 
Dessa perspectiva, a nomeação do embaixador Celso Amorim para o Ministério das Relações Exteriores constituiu um sinal de que a política externa não iria alterar significativamente seus rumos, mas procuraria rever os termos das negociações e parcerias internacionais do país, buscando a construção de alianças fora do hemisfério como forma de ampliar seu poder de influência no âmbito internacional a partir de uma agenda ativa e de um comportamento protagônico.

As prioridades externas seriam, assim, a consolidação e possível ampliação do Mercosul e a integração sul-americana, concebidas como ações para a promoção internacional brasileira. O governo passaria a dar ênfase à construção de acordos com outros parceiros, visando à aproximação comercial e econômica que tem como pressuposto que a estratégia de inserção internacional do país não deve desprezar os países do sul, onde as oportunidades podem ser extremamente atraentes para o exportador brasileiro. Assim, tomou forma o projeto de integração na América do Sul a partir da negociação do acordo Mercosul-Comunidade Andina, ao qual se somaram os acordos de complementação econômica firmados com Chile e Bolívia e os entendimentos Mercosul-Peru e Mercosul-Venezuela.

Paralelamente, organizaram-se esforços para a exploração de outras possibilidades de aproximação econômico-comercial com parceiros do mundo em desenvolvimento, em particular com o México, a África do Sul, o mundo árabe e a Associação do Sudeste Asiático, China e Índia. Sobre estes dois últimos mercados, vale ter em mente que a China ascendeu à condição de quarto maior importador de produtos brasileiros em 2002 e que o comércio bilateral com o Estado indiano praticamente triplicou em valor nos últimos anos da virada do século, alcançando 1,2 bilhão de dólares em 2003.

Quanto à África, o crescente interesse doméstico por países como Angola, Namíbia e Moçambique, bem como por negócios e empreendimentos conjuntos com o Brasil, tornou possível a articulação, pelo governo brasileiro, da negociação de dois acordos de preferências com vistas à constituição de uma zona de livre comércio entre Mercosul-SACU (União Aduaneira da África Austral) e Mercosul-SADC (Comunidade para o Desenvolvimento da África Austral). Além disso, proporcionou a articulação mais clara de representantes de movimentos sociais sobre a temática africana.

Como veremos mais adiante, no Atlântico, a política em direção à África tornar-se-ia prioridade. Sinal disso é que, durante seu primeiro mandato, o presidente Lula realizou quatro viagens a esse continente, visitando um total de dezessete países em pouco mais de dois anos. Em seu conjunto, 
2. Fórum de iniciativa trilateral entre Brasil, Índia e África do Sul. tais iniciativas viriam sinalizar a intenção governamental de promover um equilíbrio em relação ao que permanece sendo fatores constantes na estratégia de inserção internacional do país desde o governo Sarney: adensamento das relações com as grandes potências (com destaque para os Estados Unidos) e criação de condições necessárias ao ingresso de Investimento Externo Direto (IED). Apesar da importância desses dois elementos para a promoção internacional brasileira, a partir do governo Lula observam-se esforços consideráveis para a construção de acordos e espaços que garantam maiores alternativas e, consequentemente, maior capacidade de barganha ao país no plano global, a fim de que o Brasil seja compreendido como ator de características diferenciadas e, portanto, capaz de exercer papel de protagonista no plano internacional.

Considerando o ciclo de liquidez internacional e a tendência de melhoria das condições de financiamento externo, tais ações convergiriam para reafirmar, de forma significativamente otimista, o caráter universalista da diplomacia brasileira em sua estratégia de diversificação de parcerias. Esse ativismo do governo Lula também se traduziu na formação do G-20 e do IBAS $^{2}$. O primeiro foi formado pouco antes da reunião ministerial de Cancún, em setembro de 2003, quando o Brasil buscou a formação de um grupo de países interessados no fim dos subsídios internos às exportações de produtos agrícolas e em um maior acesso aos mercados norte-americano, europeu e japonês.

Nessa coalizão, como em outras alianças sul-sul, a administração Lula procurou, para além da ampliação dos benefícios econômicos individuais, a construção compartilhada de uma identidade comum, calcada em compromissos com uma ordem social e econômica mais "justa” e "igualitária”. Quanto ao IBAS, surgiu como proposta governamental de criação de um foro de coordenação e cooperação que reúne Índia, Brasil e África do Sul, descrito pelo atual ministro das Relações Exteriores como "um grupo que, juntamente com China e Rússia, deverá assumir papel internacional crescente nas próximas décadas" (Amorim, 2005, p. 7). Nos dois casos, depreende-se que o governo segue a mesma proposta: articular uma agenda comum entre o grupo de países exportadores agrícolas do mundo em desenvolvimento em favor de uma maior liberalização do comércio para a agricultura e, portanto, contrária aos subsídios agrícolas. Particularmente em relação à coalizão Brasil, Índia e África do Sul, acrescente-se que se trata de uma política voltada para a concretização de parcerias no âmbito sul-sul capaz de favorecer o alcance de um objetivo constante da diplomacia brasi- 
leira: o desenvolvimento, articulado a uma estratégia pautada pela relativa autonomia que cria em relação às economias desenvolvidas.

Dessa forma, a diplomacia do governo Lula tomaria lugar de destaque na agenda política brasileira. Como se pretende demonstrar na próxima seção, a preocupação em recuperar espaços na África e em construir novos acordos nos mais distintos foros e regiôes daria um tom marcadamente ativista à política externa brasileira, que buscaria, na articulação com os países em desenvolvimento, a promoção de uma agenda comum e ao mesmo tempo a diversificação dos vínculos com os países desenvolvidos, no intuito de conseguir acesso a mercados e a investimentos, além da conquista de um assento permanente no Conselho de Segurança da ONU.

O terceiro tópico aqui abordado centra atenção nas relações comerciais Brasil-África no referido governo. Nas considerações finais, são retomados os principais pontos abordados.

\section{Relações Brasil-África: um ponto de inflexão}

A despeito da continuidade observada no plano econômico, a política externa do governo Lula é um dos setores que melhor reflete as posiçōes tradicionais do PT, pois o discurso e a prática diplomática convergem para a construção de alianças preferenciais com parceiros no âmbito das relações sul-sul. Sinal disso é que o continente africano passou a ser encarado como uma das áreas de maior investimento em termos diplomáticos do governo, que, ao longo do primeiro mandato, não apenas tornou prioridade a reabertura dos postos diplomáticos fechados durante a administração FHC como ainda os ampliou no continente africano.

Desse modo, nos quatro primeiros anos, o governo Lula reabriu embaixadas desativadas na gestão FHC e inaugurou representaçôes diplomáticas e um consulado geral, totalizando treze novos postos, o que elevou a presença diplomática brasileira no continente africano de dezoito para trinta embaixadas e dois consulados gerais. Movimento que, deve-se registrar, proporcionou maior intensidade nas relaçôes Brasil-África, uma vez que também se pôde observar o interesse de vários Estados africanos na abertura de postos diplomáticos no Brasil. Entre 2003 e 2006, o número de embaixadores africanos acreditados em Brasília saltou de dezesseis para 25 .

Ademais, o governo Lula adotou medidas administrativas no âmbito do Ministério das Relações Exteriores para assegurar a ampliação da presença brasileira no continente africano, merecendo destaque o desmembramento 
do Departamento da África e do Oriente Médio, que veio dar lugar à reativação de um departamento voltado exclusivamente para o continente africano. Nesse ponto, também se ressalta a criação da Divisão da África-III (DAF-III), que veio juntar-se às duas já existentes (DAF-I e DAF-II). A reabertura e a ampliação de postos diplomáticos, bem como a reestruturação administrativa, devem ser encaradas, portanto, como resultado direto do interesse governamental na ampliação da presença brasileira no continente africano, com consequente efeito inverso: o interesse dos Estados africanos em ampliar sua presença no Brasil.

Nesses termos, não há como negar o fato de que, apesar de fragilizada ao longo da década de 1990, a política africana ainda mantém vitalidade no plano diplomático brasileiro, adquirindo relevância singular quando consideradas as açôes e os discursos realizados pelo atual governo para o continente africano. Desse modo, verifica-se que há ajustes consideráveis na agenda diplomática brasileira, que passa a privilegiar regiōes e parcerias até então não valorizadas pela gestão FHC. Além disso, observa-se que a execução da política externa brasileira para a África se distinguiu da prática desenvolvida pelos governos predecessores, que enfocaram sobremaneira as relações do Brasil com os Palop (Países Africanos de Língua Oficial Portuguesa). $\mathrm{Na}$ atual gestão, verifica-se nítido esforço para a ampliação do raio de atuação da diplomacia brasileira no continente africano. O próprio roteiro das viagens presidenciais é claro exemplo do interesse em ampliar a presença brasileira na África, que procura não se limitar a apenas uma sub-região ou um organismo multilateral, como a CPLP. Sem desconsiderar as parcerias tradicionais, intenta-se favorecer o estreitamento das relaçóes do Brasil com organismos regionais africanos, como a União Africana (UA), a Nova Parceria para o Desenvolvimento da África (Nepad), a Comunidade Econômica dos Estados da África Ocidental (Cedeao), a União Aduaneira da África Austral (SACU) e a Comunidade para o Desenvolvimento da África Austral (SADC), de forma a aproveitar as possibilidades políticas e econômicas no âmbito da cooperação sul-sul.

Por esse prisma, é correto considerar que, apesar da aparente fragilidade do relacionamento comercial afro-brasileiro, com participação marginal no intercâmbio comercial do país ao longo da década de 1990, o continente africano ainda detém uma posição privilegiada na política externa brasileira. Nesse processo de redefinição, as possibilidades abertas para a política africana são inúmeras, pois, assim como o Brasil nas décadas de 1980 e 1990, um crescente número de Estados africanos, a exemplo de África do 
Sul e Angola, tem registrado profundas transformações em suas estruturas políticas, econômicas e sociais. Além da adoção de regimes políticos democráticos, observa-se a implementação de políticas econômicas de priorização da estabilidade macroeconômica, consideradas essenciais para o desenvolvimento sustentado; e, ao mesmo tempo, redefinem-se as estratégias de industrialização, que não se realizam pela substituição de importações, mas, antes, pela integração das respectivas economias aos fluxos internacionais de comércio e investimento.

Somente em 2005, o fluxo de IED no continente atingiu a cifra de 31 bilhões de dólares. Ainda que esteja concentrado em poucos países, é expressivo notar que nesse ano o aumento de IED chegou a 78\% em comparação com 2004, sendo ocasionado principalmente por um forte crescimento na rentabilidade das empresas que operam no continente e pelo alto preço das commodities lá produzidas (Gráfico 1). No continente, a África do Sul foi o país que mais recebeu investimentos em 2005 (6,4 bilhões de dólares), seguida pelo Egito, Nigéria, Marrocos, Sudão, Guiné Equatorial, República Democrática do Congo, Argélia, Tunísia e Chade.

GRÁFICO 1

Preço das Commodities no Mercado Internacional (1999-2008)

(Index, $1995=100)$

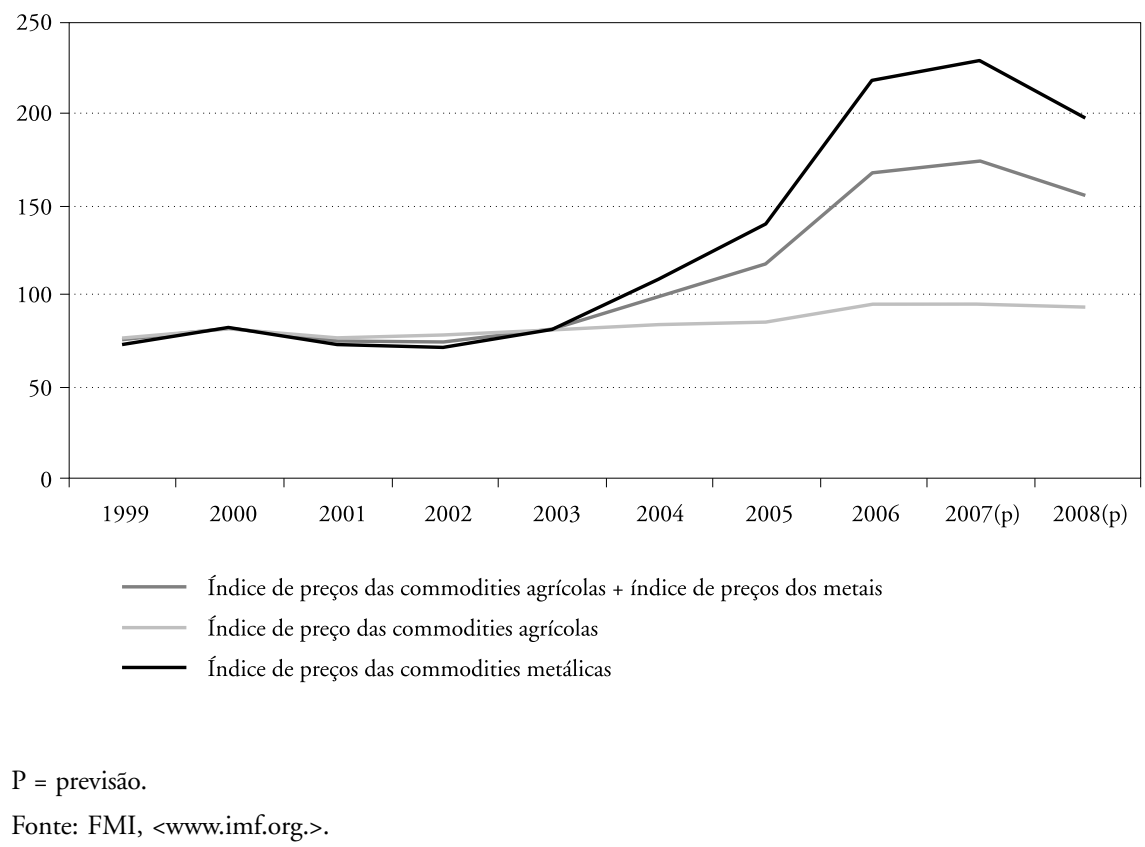


Os aportes realizados no continente foram concentrados em setores como petróleo, gás e mineração. Segundo as estimativas da UNCTAD (2005), o fluxo de investimentos para a África deverá continuar a crescer devido ao grande número de projetos já anunciados na região, à quantidade expressiva de investidores interessados nos recursos africanos e a políticas geralmente favoráveis ao recebimento de IED no continente. No mesmo sentido, as estimativas da OCDE (2006) apontam para o fato de a atividade econômica no continente africano ter crescido, em média, 5\% em 2005, prevendo-se alcançar cifras em torno de 5,8\% e 5,5\% em 2006 e 2007, respectivamente.

Nesse cenário, os países exportadores de petróleo ganham destaque importante, por conseguirem ultrapassar as demais economias em função das margens significativas obtidas com a venda desse produto no mercado internacional. Embora o continente africano ainda seja palco de graves problemas humanitários, a perspectiva para grande parte de seus Estados continua sendo mais favorável do que a dos últimos anos.

Em compasso com a acentuada expansão da economia global, a crescente demanda por recursos energéticos, como petróleo e outros materiais industriais brutos, tem elevado os preços e favorecido a possibilidade de aumento significativo da ajuda oficial ao desenvolvimento na África, amplamente liderado pela isenção das dívidas e pela assistência emergencial, assim como a melhoria da estabilidade macroeconômica contribuiu para essas perspectivas econômicas positivas. Por outro lado, apesar do aumento dos preços do petróleo, a inflação permaneceu em níveis historicamente baixos. Em consequência, em muitos países houve melhora no equilíbrio comercial, com maiores lucros para os exportadores de petróleo e de minérios de metal.

Após décadas sem crescimento, a economia africana passa a dar sinais de melhora sensível. Durante a última década, o continente tem observado não apenas a aceleração constante do crescimento econômico, mas também novas oportunidades de comércio e investimentos. Isso reforça o esforço generalizado dos Estados africanos na promoção de reformas macroeconômicas e políticas, em que a UA, a SADC, a Cedeao e a Nepad são sinais claros não apenas de boa vontade, mas de interesses definidos por parte de seus membros de encarar de forma realista os problemas do continente; assumindo, com todas as dificuldades inerentes a projetos desse porte, as responsabilidades derivadas da cooperação em prol do desenvolvimento.

Por esse prisma, o lançamento da Nepad, da UA, o consenso de Monterrey, relativo ao financiamento do desenvolvimento, e a implementação 
da iniciativa dos PPME (Países Pobres Muito Endividados), assim como os compromissos assumidos na Cimeira do G8 em Gleneagles, representam fatos importantes para o fluxo crescente de financiamento com vistas ao desenvolvimento dos Estados africanos.

Deve-se destacar também, em particular, o potencial da Comunidade dos Países de Língua Portuguesa (CPLP) e da Zona de Paz e Cooperação do Atlântico Sul (Zopacas) para a diplomacia brasileira na construção de acordos de âmbito multilateral, mecanismos capazes de reunir grupos de nações que, em torno de temas específicos ou genéricos, favoreçam objetivos afins nos fóruns globais. Ademais, tanto a CPLP como a Zopacas guardam como potencial servir de locus de intersecção entre vários processos de integração econômica em curso na região do Atlântico Sul, capazes de implementar o intercâmbio entre Mercosul, SADC e Cedeao.

Também a África Subsaariana apresenta-se como um ambiente em que a diplomacia nacional pode exercitar sua capacidade de intermediação e de resolução de litígios e conflitos, projetando internacionalmente a imagem do país como ator protagonista na construção de uma provável ordem mundial voltada mais para os compromissos dos países em desenvolvimento do que para as economias avançadas. Para isso, a participação de tropas brasileiras em missōes de paz da ONU, como nos casos de Angola e Moçambique, reveste-se de importância singular. A presença das tropas brasileiras no continente africano vai ao encontro tanto das expectativas e das necessidades dos parceiros africanos como do interesse do Brasil em assegurar objetivos próprios em plano global. O envio de tropas para Angola e Moçambique, ao mesmo tempo em que colabora para os processos de paz no continente, promove a imagem brasileira, tornando-se uma espécie de vitrine da diplomacia do país, capaz de garantir apoio dos Estados africanos em seu pleito por um assento permanente do Conselho de Segurança da ONU.

No plano econômico, a diplomacia presidencial tem favorecido significativamente o setor empresarial brasileiro no continente africano. Exemplo disso é o crescente número de empresas brasileiras, sobretudo as exportadoras de serviços, empenhadas na consecução de projetos no continente africano. Também merece destaque o fato de a Companhia Vale do Rio Doce ter sido a vencedora da concorrência para a exploração do complexo carbonífero de Moatize, situado no norte de Moçambique, contribuindo, assim, para o estreitamento das relações com o Brasil.

Em Angola, a interação política tem favorecido enormemente as relações comerciais e os investimentos brasileiros no país. O atual governo am- 
pliou as linhas de crédito ao Estado angolano de modo a atingir uma soma de 580 milhões de dólares no triênio 2005-2007, permitindo a conclusão da hidroelétrica de Capanda, as exportações de automóveis e viaturas de polícia, além da contratação de novos projetos nas áreas de infraestrutura, saneamento e agricultura. Os investimentos crescentes da Petrobrás na África são outro exemplo da consolidação da presença brasileira no continente, com a ampliação de suas operações na Tanzânia.

Cabe avaliar, portanto, em que medida tais transformações e oportunidades são ou podem vir a ser aproveitadas pelo Brasil e pelos parceiros africanos. No próximo tópico, são analisadas as relações comerciais Brasil-África ao longo do período estudado. Para além do crescimento da corrente de comércio, atualmente abrem-se oportunidades importantes para o adensamento e a intensificação das relações entre Brasil e África, o que, obviamente, coloca em debate a capacidade de articulação, em plano doméstico nacional, de estratégias e projetos capazes de contribuir para a dinamização e a potencialização do fluxo de comércio e investimentos do Brasil na África.

\section{A dinâmica comercial e as relações Brasil-África}

A despeito das grandes transformações na realidade brasileira entre as décadas de 1980 e 1990, sua economia tem registrado, ao longo do mesmo período, um ritmo de crescimento inferior ao da média internacional. Dado ilustrativo dessa situação pode ser verificado ao se constatar que 1995 foi o último ano em que a economia brasileira expandiu-se mais do que a média mundial. Dez anos depois, o PIB brasileiro ampliou-se em 2,3\%; demonstrando um crescimento tímido, uma vez que as estimativas do Fundo Monetário Internacional (FMI) apontam para uma expansão de 4,3\% para o restante do mundo. Excetuando-se os anos de 2003 e 2004, quando o ritmo de crescimento do PIB brasileiro aproximou-se do ritmo mundial, é flagrante perceber que o baixo crescimento econômico nacional reflete um cenário preocupante, pois indica que o país vem perdendo importância relativa na economia mundial.

No último decênio, também o PIB brasileiro tem se caracterizado por nítida regularidade: entre 1996 e 2005, a taxa média anual de expansão no período foi de 2,2\% - exatamente igual à média dos últimos cinco anos (2001-2005). A consequência direta dessa regularidade é o baixo crescimento do PIB, o que faz o país, em comparação às demais nações, ficar mais pobre. Exemplo disso é que, entre 1996 e 2005, enquanto a economia 
mundial cresceu 45,6\%, o PIB brasileiro expandiu-se 22,4\%. Nesse mesmo período, a média de expansão do PIB per capita no Brasil foi de 0,7\% ao ano, ficando entre uma das menores do mundo e particularmente distante dos valores alcançados por países emergentes da Ásia (China e Índia), que lideraram o crescimento.

Deve-se ressaltar, contudo, que o baixo crescimento econômico não é uma particularidade brasileira, mas um fenômeno regional. À exceção do Chile, todos os demais países sul-americanos cresceram menos do que a média mundial nesse último decênio. Porém, um dado que chama a atenção é a renda per capita brasileira, que cresceu menos até do que seus pares emergentes da América Latina. Ao longo dos últimos dez anos, enquanto o PIB per capita brasileiro expandiu-se a uma taxa menor que a da Argentina $(2,1 \%)$, o ritmo de crescimento do PIB per capita no México foi três vezes maior que o do Brasil, e o do Chile, quatro vezes maior.

$\mathrm{O}$ fraco ritmo de expansão do PIB brasileiro tem contrastado com o intenso crescimento do restante do mundo, cujo resultado é a perda da importância relativa do país na economia mundial. Mantidas as atuais condições, a Confederação Nacional da Indústria considera que levaria cem anos para o PIB brasileiro dobrar de tamanho - o que significaria o país ser rapidamente ultrapassado pelos emergentes da Ásia e se distanciar, cada vez mais, das economias mais desenvolvidas (cf. CNI, 2006).

Nesse cenário, em que pese a necessidade de aumento da taxa de investimentos (de cerca de $16 \%$ para pelo menos 25\%) em relação ao PIB, a busca por novos mercados e a ampliação da corrente de comércio com os mercados existentes é imprescindível para o Estado brasileiro. A taxa de crescimento da produção, modesta em 2003 e superior a 5\% em 2004, foi obtida graças a um formidável aumento das exportações e à geração de um importante saldo comercial externo. Diante do crescimento da economia global e do comércio internacional (Gráfico 2), paralelamente à elevação dos preços internacionais das commodities e a uma taxa de câmbio favorável aos exportadores brasileiros, no período compreendido entre 2003 e 2006 o nosso setor externo passou a apresentar números significativos, com as exportações e importações batendo sucessivos recordes (Gráfico 3).

Entre 2003 e 2006, o governo foi favorecido também pelas condições internacionais em termos de liquidez e crescimento, que resultaram na retomada dos fluxos de capitais voluntários. Como mostra o Gráfico 4, em 2000 o fluxo de IED para o Brasil atingiu o recorde de 32,8 bilhões de dólares. Contribuíram para esse movimento o ambiente macroeconômico 
estável, e as políticas de desregulamentação e de privatização implementadas a partir de meados da década de 1990. Contudo, esse fluxo não se manteve de forma sustentada. Em função de turbulências no cenário internacional e de instabilidades causadas pela transição política, em 2002 o ingresso de IED sofreu um acentuado recuo.

GRÁFICO 2

Volume do Comércio de Bens e Serviços no Mundo

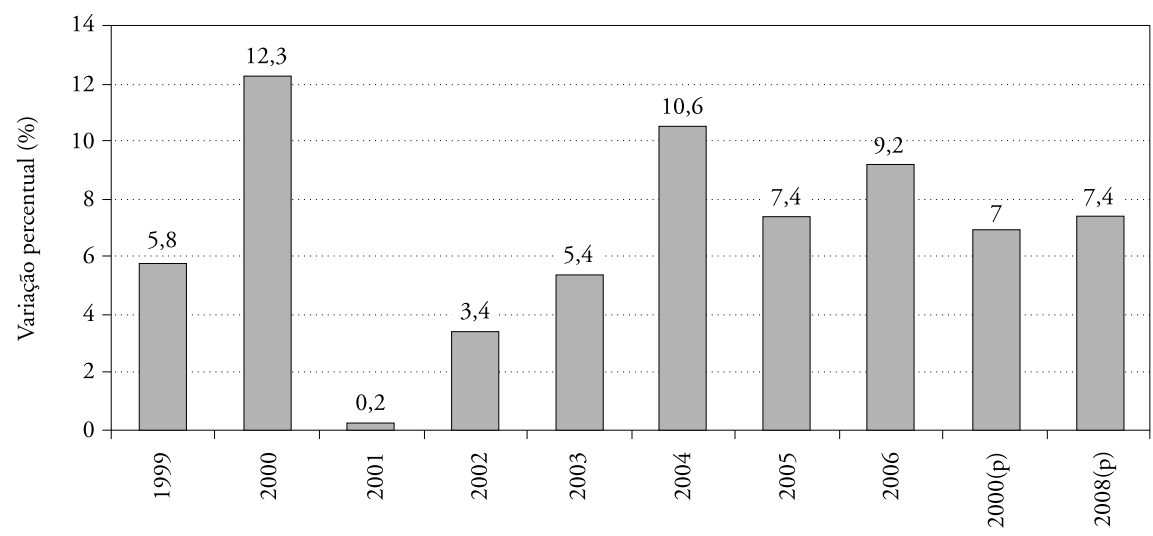

$\mathrm{P}=$ previsão.

Fonte: FMI, <www.imf.org/external/data.htm>.

GRÁFICO 3

Brasil: Exportação e Importação (média móvel trimestal), 2003-2006

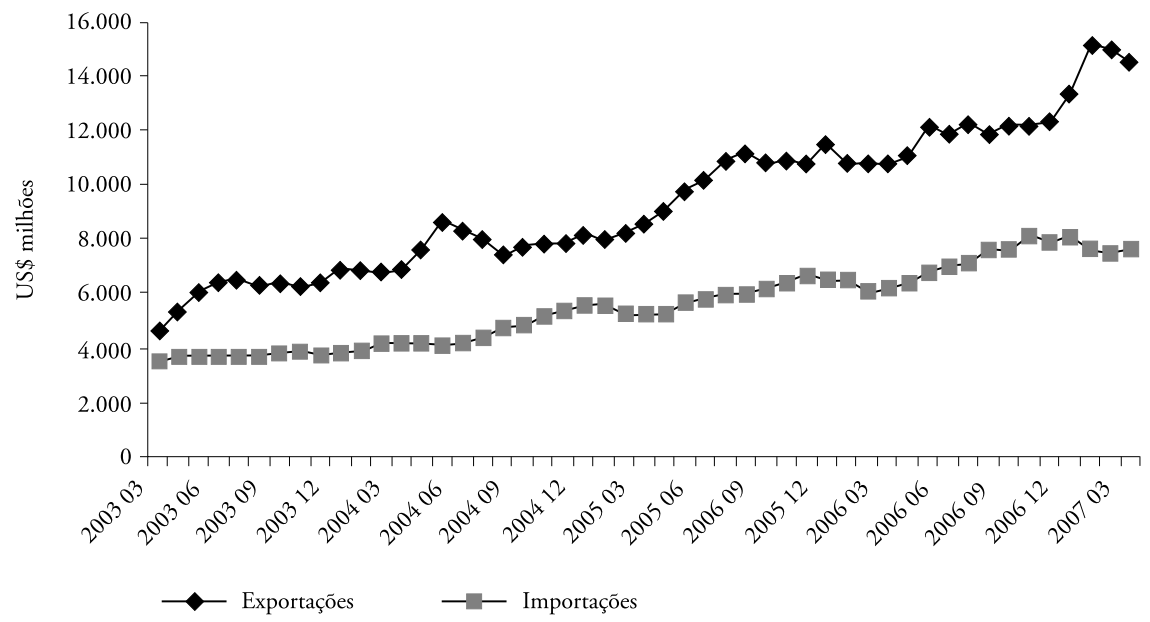

Fonte: Elaborado a partir de dados do MDIC, <www.mdic.org.br>. 
GRÁFICO 4

Brasil: Ingresso de IED (1999-2006)

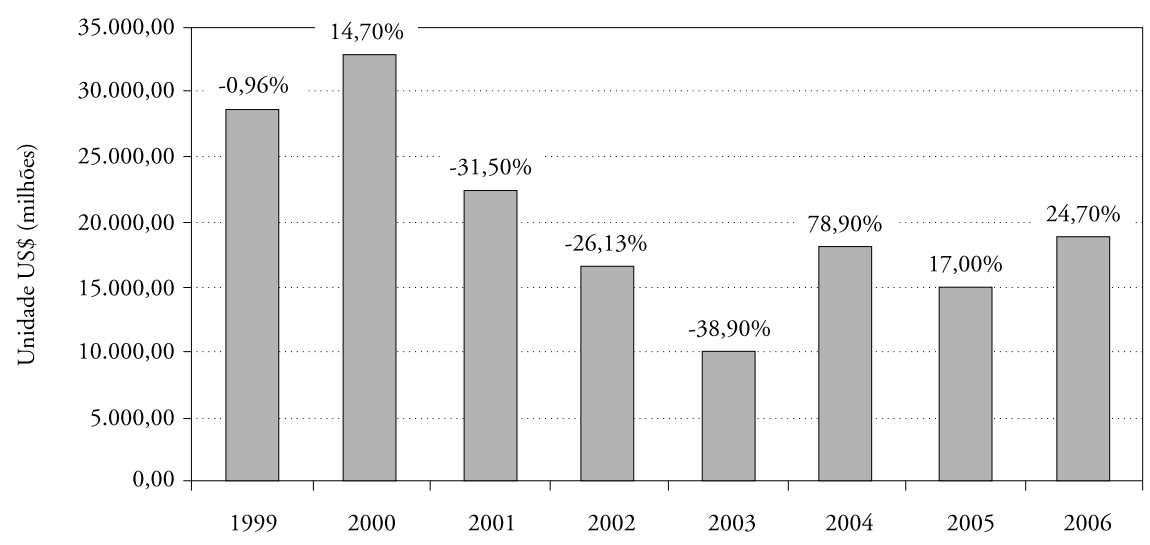

Fonte: Elaborado a partir de dados do Banco Central, <www.bcbc.org.br>.

Já em 2003, os valores de entrada de IED no Brasil foram de 10,1 bilhões de dólares, representando uma queda de cerca de 30\% em comparação ao ano anterior e confirmando a tendência declinante observada a partir de 2001. Em 2004, no entanto, o ingresso de IED voltou a apresentar alguma recuperação, atingindo a cifra de 18,2 bilhões de dólares. Assim, após 2004 o Brasil passou a ser beneficiado pelo crescimento dos fluxos de IED, o que, segundo a UNCTAD (2005), reflete um movimento de retomada dos investimentos externos diretos para os países periféricos.

Contudo, em contraposição ao cenário internacional favorável, de acordo com o relatório mundial de exportações divulgado pela OMC (2007), apesar de ter o nono maior PIB do mundo, em 2006 o Brasil ficou em 240 lugar no ranking de exportadores, detendo apenas $1,1 \%$ do mercado mundial (equivalente a 137 bilhões de dólares), percentual bem inferior ao de países de porte similar, como Coreia do Sul, com 326 bilhões de dólares (11 $1^{\circ}$ lugar), Rússia, com 305 bilhões de dólares (13o lugar) e México, com 250 bilhões de dólares (15\% lugar).

Considerando que o aprofundamento do processo de globalização tenha como efeito direto o aumento do volume de comércio internacional (exportaçôes mais importaçōes), que praticamente dobrou nos últimos dez anos no mundo, atingindo cerca de 20 trilhōes de dólares, constata-se que a presença brasileira é inferior à sua potencialidade. Ao contrário de países como México e Rússia, que concentram suas exportações basicamente em petróleo, o Brasil detém uma pauta significativamente diversificada. Por outro lado, a própria diversificação da pauta exportadora também possibi- 
lita ao Brasil atingir mercados de destino bastante variados: $27 \%$ para Europa, 20\% para Estados Unidos, 23\% para demais países da América Latina, 15\% para a Ásia e outros 15\% para países árabes, África e Oceania.

Diante desse quadro, a ampliação das exportações brasileiras (com consequente aumento de sua participação no comércio mundial), seja em relação às áreas mais dinâmicas do mercado mundial, seja em relação a mercados alternativos (ou complementares), torna-se uma necessidade primordial ao país. Nesse sentido, a ampliação e o adensamento das relaçôes comerciais com os países africanos revestem-se de importância significativa para o Brasil, uma vez que, além do prestígio e do capital político-diplomático construído pelo país junto à outra margem do Atlântico, o continente africano tem registrado melhoras consideráveis não apenas no plano político, mas também no econômico e comercial.

No que concerne às relações comerciais do Brasil com o continente africano, desde 2002 o valor do intercâmbio triplicou. As exportaçôes brasileiras para a África aumentaram mais de 487\% no período que vai de 1996 a 2006, e o maior crescimento foi observado no período de 2002 a 2006 - 315\% em quatro anos. No que se refere às importações, houve um acréscimo de $478 \%$ nos últimos dez anos, e as cifras saltaram de 2,6 bilhōes de dólares em 2002 para 8 bilhões de dólares em 2006. A corrente de comércio nos dois sentidos passou de 6 bilhões de dólares em 2003 para 15 bilhões em 2006.

Considerando estritamente o intercâmbio Brasil-África Subsaariana, África do Sul, Angola e Nigéria podem ser identificados como alternativas estratégicas para a diplomacia brasileira, uma vez que o potencial de crescimento e as demandas por investimentos podem beneficiar um grande número de empresas nacionais. Essa percepção é sobremaneira corroborada pela análise do intercâmbio comercial entre o Brasil e o continente africano (Gráficos 5 e 6), com destaque, nos últimos anos, às relações comerciais com Angola, Nigéria e África do Sul (Gráficos 7 e 8), que juntos representam em média $48 \%$ do total das exportações brasileiras para aquele continente e 53\% das importações africanas para o Brasil.

As exportações brasileiras para esses três países atingem valores expressivos em relação ao montante comercializado com a África em conjunto, permitindo observar uma grande similaridade nos valores por categorias de produtos no que se refere a Nigéria e África do Sul, que juntos representam $82 \%$ dos valores exportados pelo Brasil para aquele continente no período de 2003 a 2006. Ainda quanto à análise das relações comerciais por categorias de produtos (os fatores agregados), é importante ressaltar que as expor- 
tações brasileiras para os Estados africanos, ao longo dos últimos vinte anos, indicam a predominância de produtos manufaturados, seguidos em proporção bem menor pelos produtos ditos básicos (Tabelas 1 e 2)

\section{GRÁFICO 5}

Importaçôes Brasileiras do Continente Africano (2003-2006)

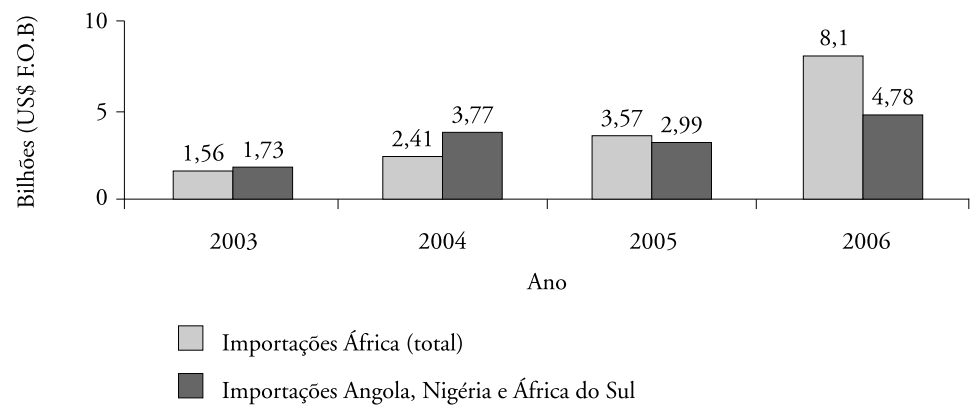

Fonte: Elaborado a partir de dados do MDIC, www.mdic.gov.br.

GRÁFICO 6

Exportaçôes Brasileiras para o Continente Africano (2003-2006)

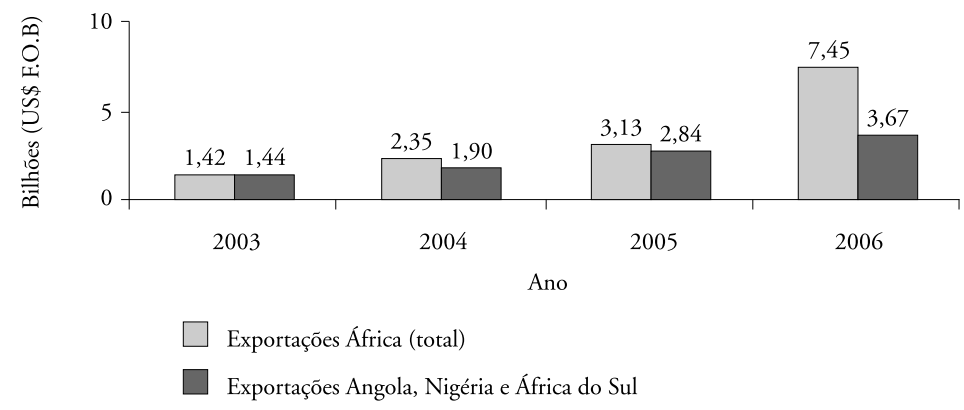

Fonte: Elaborado a partir de dados do MDIC, www.mdic.gov.br.

\section{GRÁFICO 7}

Intercâmbio Brasileiro com Angola, Nigéria e África do Sul (2003-2006)

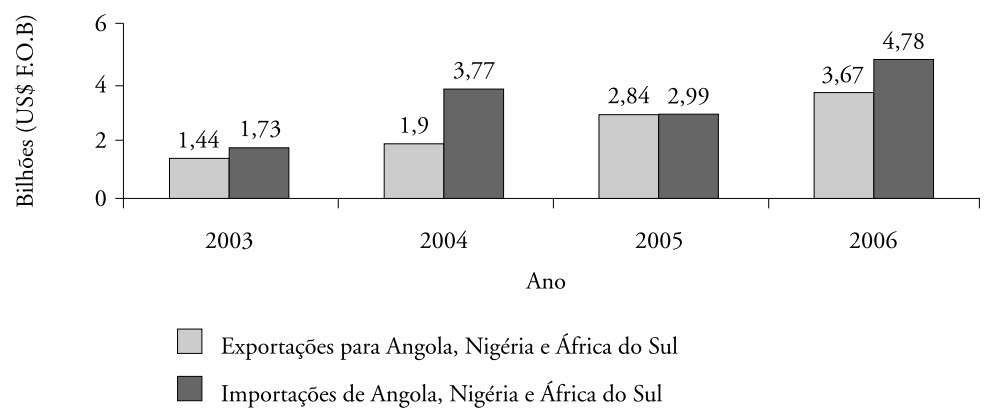

Fonte: Elaborado a partir de dados do MDIC, www.mdic.gov.br. 
A política africana do governo Lula (2003-2006), pp. 185-209

GRÁFICO 8

Intercâmbio Brasileiro com o Continente Africano (2003-2006)

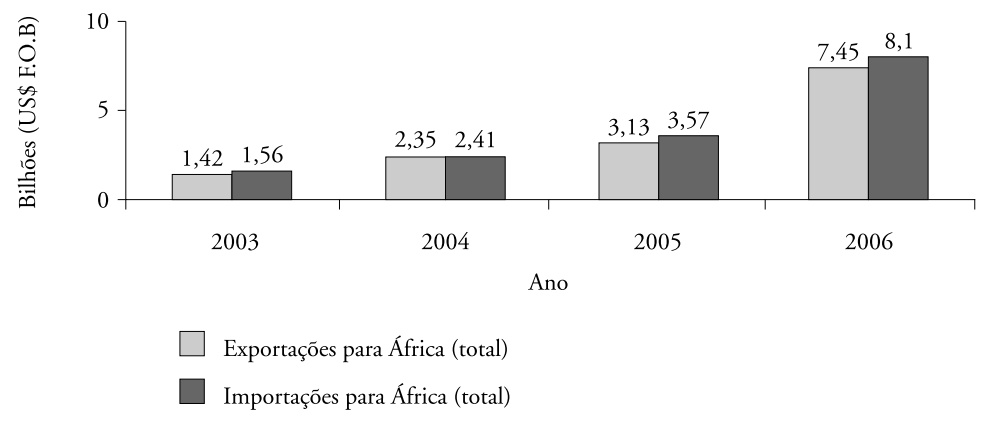

Fonte: Elaborado a partir de dados do MDIC, www.mdic.gov.br.

TABELA 1

Exportaçōes Brasileiras para a África por Fatores Agregados (1985-2006)

VALORES POR CATEGORIAS DE PRODUTOS (US\$ F.O.B)

\begin{tabular}{l|c|c|c|c|c}
\hline & TOtAL & BÁsicos & SEMIMANUFATURADOS & MANufATURADOS & Op. ESPECIAIS \\
\cline { 2 - 6 } TOTAL ÁFriCA & 45.608 .240 .890 & 8.072 .096 .798 & 7.217 .503 .893 & 30.249 .392 .379 & 69.247 .820 \\
Participação (\%) & $100,0 \%$ & $17,7 \%$ & $15,8 \%$ & $66,3 \%$ & $0,2 \%$ \\
\hline
\end{tabular}

Fonte: Elaborado a partir de dados do MDIC, www.mdic.gov.br.

TABELA 2

Totais das Exportaçoes Brasileiras para os Principais Parceiros Comerciais na África por Fatores Agregados (1985-2006)

\begin{tabular}{|c|c|c|c|c|c|}
\hline \multicolumn{6}{|c|}{ VALORES POR CATEGORIAS DE PRODUTOS (US\$ F.O.B) } \\
\hline & TOTAL & BÁsICOS & SEMIMANUFATURADOS & MANUfATURADOS & OP. ESPECIAIS \\
\hline Angola & 4.782 .919 .021 & 554.714 .487 & 101.139 .666 & 4.120 .866 .277 & 4.717 .297 \\
\hline África do Sul & 8.594 .414 .676 & 1.302 .303 .510 & 599.442 .795 & 6.684 .041 .007 & 8.631 .618 \\
\hline Nigéria & 8.493 .403 .155 & 162.696 .830 & 1.000 .205 .807 & 7.319.268.699 & 11.228 .461 \\
\hline TOTAL & 21.870 .736 .852 & 2.019 .714 .827 & 1.700 .788 .268 & 18.124 .175 .983 & 24.577 .376 \\
\hline Participação (\%) & $100 \%$ & $9,2 \%$ & $7,8 \%$ & $82,9 \%$ & $0,1 \%$ \\
\hline
\end{tabular}

Fonte: Elaborado a partir de dados do MDIC, www.mdic.gov.br.

É relevante observar, ainda, que nos últimos vinte anos o saldo comercial brasileiro é positivo nas relações com Angola e África do Sul. Já com a Nigéria, no entanto, o saldo é negativo, devido às importações brasileiras de petróleo. Um recorte dos últimos três anos nessas relações comerciais possibilita perceber uma continuidade no saldo positivo das relações co- 
merciais brasileiras com Angola (1,1 bilhão de dólares) e África do Sul (2,3 bilhões de dólares), porém não com a Nigéria (negativo de 3,1 bilhões de dólares). Chama atenção o saldo positivo da balança comercial brasileira com Angola nesse período, que alcançou $42 \%$ do valor relativo aos últimos vinte anos. Fato semelhante, mas em intensidade bem menor (22\%), ocorre com a África do Sul, o que sugere um efetivo crescimento das exportações para tais países. Uma primeira caracterização dos produtos exportados pelo Brasil para esses países pode ser observada na Tabela 3.

TABELA 3

Totais das exportaçôes brasileiras para os principais parceiros comerciais na África* por fatores agregados, $1985-2006$ (US\$ bilhoes)

\begin{tabular}{|c|c|c|c|c|c|}
\hline \multicolumn{6}{|c|}{ VALORES POR CATEGORIAS DE PRODUTOS (US\$ F.O.B) } \\
\hline & TOTAL & BÁsICOS & Semimanufaturados & MANUFATURADOS & OPERAÇŌES ESPECIAIS \\
\hline Angola & 4,78 & 0,55 & 0,10 & 4,12 & 0,00 \\
\hline África do Sul & 8,59 & 1,30 & 0,60 & 6,68 & 0,01 \\
\hline Nigéria & 8,49 & 0,16 & 1,00 & 7,32 & 0,01 \\
\hline TOTAL & 21,87 & 2,02 & 1,70 & 18,12 & 0,02 \\
\hline Participação (\%) & $100 \%$ & $9,20 \%$ & $7,80 \%$ & $82,90 \%$ & $0,10 \%$ \\
\hline
\end{tabular}

*Exclusive Oriente Médio.

Fonte: Elaborado a partir de dados do MDIC, www.mdic.gov.br.

A balança comercial brasileira mantém-se negativa com a Nigéria (Tabela 3). Apesar do notável recuo das importações brasileiras de petróleo desse país no ano de 2005 - quando ocorre uma redução de $23,4 \%$ no dispêndio de divisas com a importação de óleos brutos de petróleo e reduções de $70,1 \%$ do gás liquefeito de petróleo (GLP) e 17,2\% do gás propano -, em 2006 o Brasil retomou e superou a importação de óleos brutos de petróleo nos níveis alcançados em 2004. Os recentes acontecimentos que levaram à nacionalização das reservas de gás bolivianas, com os potenciais prejuízos ao abastecimento do mercado brasileiro, poderão adensar ainda mais essas relaçôes comerciais, privilegiando as importaçôes de gás nigeriano, inexpressivas no biênio 2005-2006.

Ainda em relação à Nigéria, mesmo excetuando-se os valores das exportações brasileiras no biênio 1984-1985, e mais recentemente em 2005, que alcançaram níveis bastante representativos (outliers), a evolução do intercâmbio comercial entre os dois países revela um alto grau de dispersão (Grá- 
ficos 9 e 10). Tal fato não permite supor, sequer, uma relação de aparente estabilidade ao longo dos últimos vinte anos. Já os valores obtidos nos últimos quatro anos, apesar de sinalizarem tendência a um possível incremento das exportações, não podem ser considerados sem os devidos cuidados, haja vista o comportamento instável já descrito.

GRÁFICO 9

Evolução das Exportações Brasileiras para a Nigéria (1985-2006)

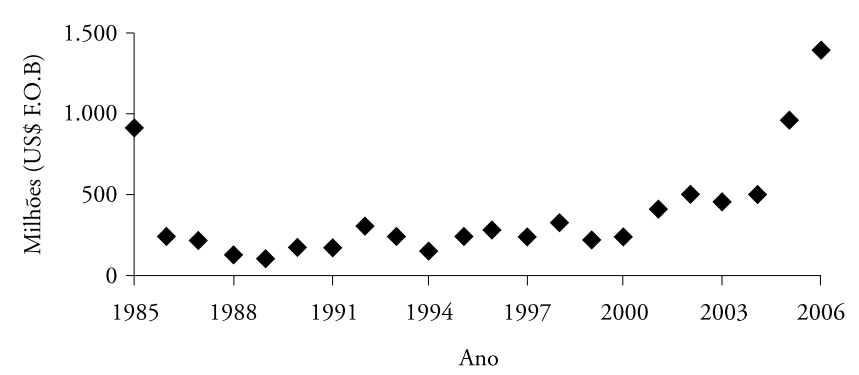

Fonte: Elaborado a partir de dados do MDIC, www.mdic.gov.br.

GRÁFICO 10

Evolução das Exportaçôes Brasileiras para a Nigéria nos últimos 48 meses (2003-2006)

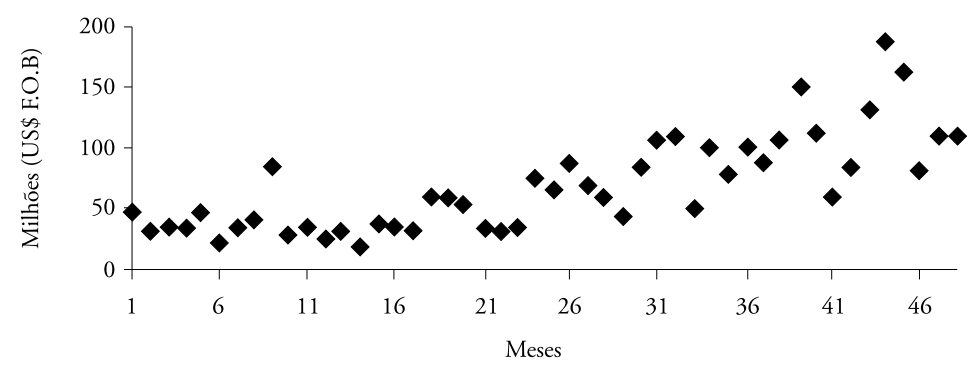

Fonte: Elaborado a partir de dados do MDIC, www.mdic.gov.br.

Ao contrário do cenário para a Nigéria, a evolução das exportações brasileiras para a África do Sul permite constatar relaçôes mais estáveis ao longo dos últimos vinte anos, indicando uma leve tendência de crescimento durante a década de 1990 seguida de um impulso mais acentuado nos últimos quatro anos (Gráficos 11 e 12). 
GRÁFICO 11

Evolução das Exportações Brasileiras para a África do Sul (1985-2006)

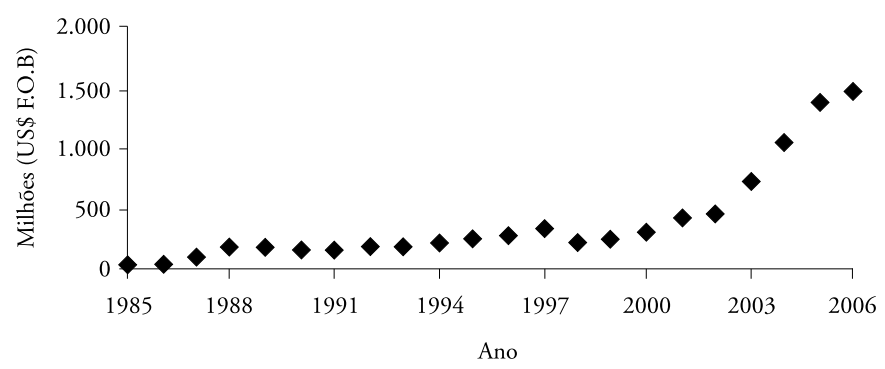

Fonte: Elaborado a partir de dados do MDIC, www.mdic.gov.br.

GRÁFICO 12

Evolução das Exportações Brasileiras para a África do Sul nos últimos 48 meses (2003-2006)

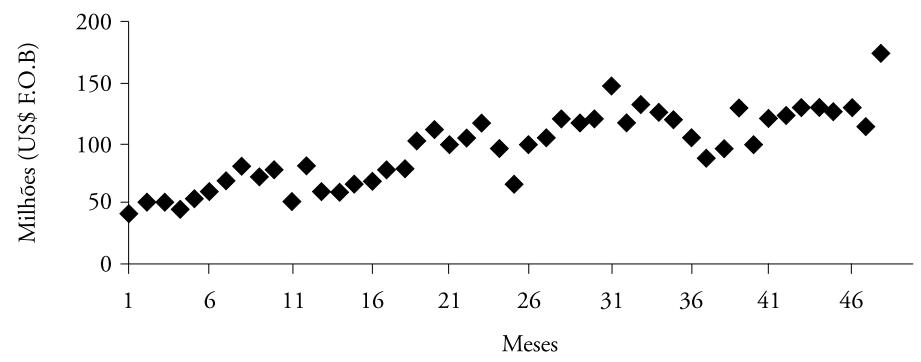

Fonte: Elaborado a partir de dados do MDIC, www.mdic.gov.br.

Considerados os mesmos períodos, as exportações brasileiras para Angola, particularmente, sugerem um crescimento apreciável, conforme se pode observar nos Gráficos 13 e 14. Contudo, uma análise de correlação das variáveis envolvidas indica um fator de 0,52 (correlação moderada), o que mostra um comportamento ainda bastante suscetível a oscilações nessas relações. Daí a importância da revisão da política externa africana desenvolvida pelo Brasil ao longo das últimas décadas, pré-requisito para "transformar os laços de amizade que nos unem aos povos da África em progresso econômico e social, em benefício mútuo" (Amorim, 2003).

De acordo com os dados expostos, é possível considerar que o comércio exterior tem implicações evidentes para a política externa. Particularmente para o Brasil, elas se manifestam pela necessidade histórica da adoção de medidas que incrementem substancialmente as exportaçóes e mantenham as importaçōes em nível moderado, contribuindo para a regularização das contas públicas e, ao mesmo tempo, promovendo condiçóes capazes de 
gerar superávit para inversōes da União. Evidentemente, apenas esse aspecto já é mais do que suficiente para gerar acalorada polêmica, pois recorta, indistintamente, grupos de interesses, partidos políticos e organizações governamentais e não governamentais, cujos motivos são as próprias preferências de alinhamento na ordem internacional.

GRÁFICO 13

Evolução das Exportações Brasileiras para Angola (1985-2006)

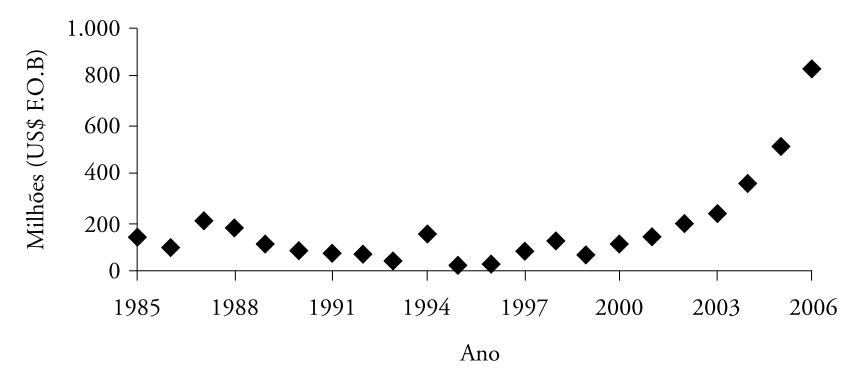

Fonte: Elaborado a partir de dados do MDIC, www.mdic.gov.br.

GRÁFICO 14

Evolução das Exportaçôes Brasileiras para Angola nos últimos 48 meses (2003-2006)

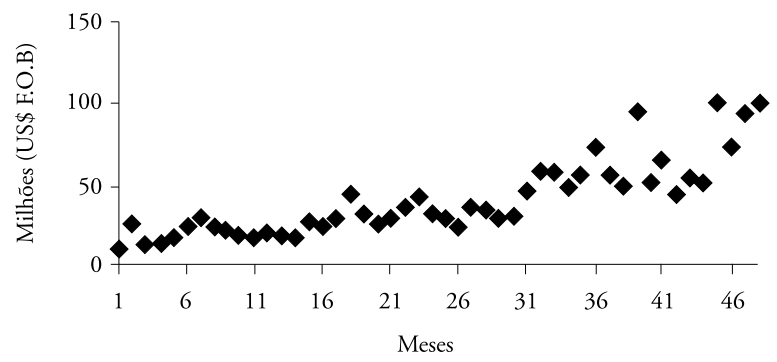

Fonte: Elaborado a partir de dados do MDIC, www.mdic.gov.br.

Por esse prisma, pode-se considerar a tese de que a política externa brasileira para a África, para manter coerência entre o discurso diplomático e a manutenção de seu sentido estratégico, necessita definir os vetores capazes de articular os interesses nacionais às possibilidades e aos interesses definidos pelos Estados africanos. E, nesse aspecto, a adoção de políticas que valorizem investimentos na área energética demonstra-se particularmente relevante, fato que se torna ainda mais evidente quando, ao longo da última década, a ação do Itamaraty para o continente africano transparece na opção por parcerias preferenciais - com destaque para África do Sul, Angola e Nigéria. 
No período analisado, as relações comerciais Brasil-Angola têm sido intensamente favorecidas pelas descobertas offshore. Nos últimos anos, Angola transformou-se numa área líder em exploração e prospecção de petróleo no Oeste da África, tornando-se o segundo maior produtor da África Subsaariana, com Cabinda sendo responsável por mais da metade da produção do petróleo angolano. Atento a essas transformações, o Brasil tem buscado forjar projetos político-comerciais orientando-se pela percepção de que Angola é um parceiro não apenas geográfico e cultural, mas economicamente promissor.

Em relação à África do Sul, a política externa brasileira é diretamente influenciada pelo início do processo de democratização e pela superação do apartheid, que durante décadas relegou o Estado sul-africano a uma condição marginalizada nos principais fóruns e organismos mundiais. País com quem o Brasil mantém relações comerciais desde a década de 1940, a África do Sul surge como parceiro em acordos entre o Mercosul e a União Aduaneira da África Austral. Mesmo tendo poucas reservas de petróleo, é um grande produtor e exportador de carvão. Por esse motivo, têm sido alvo da atenção brasileira os investimentos realizados pelo país na construção de uma indústria de combustíveis sintéticos (synfuel), altamente desenvolvida e que utiliza não só as abundantes reservas de carvão, como também o condensado e o gás natural offshore de Mossel Bay.

Já o comércio do Brasil com a Nigéria tem sido intensificado desde a década de 1980: "A participação brasileira no mercado nigeriano foi tão importante entre 1985 e 1986 que o Brasil chegou a ultrapassar a relevância econômica das compras nigerianas da Inglaterra” (Saraiva, 1994, p. 318). Membro da Organização dos Países Exportadores de Petróleo, a Nigéria é um dos maiores exportadores de petróleo do mundo, tendo a Nigerian $\mathrm{Na}$ tional Petroleum Company (NNPC), empresa estatal de petróleo, como o maior player na indústria petrolífera do país, tanto no upstream como no downstream. A Chancelaria tem concentrado esforços na criação de mecanismos que permitam ao Brasil efetivamente promover maior dinamização das relações econômicas com a Nigéria, hoje centradas justamente na constituição de canais que possibilitem a prospecção e importação de petróleo por empresas brasileiras.

Assim, o adensamento das relaçôes comerciais Brasil-África tem se tornado uma realidade. Apesar de não ser possível determinar com precisão quais são os impactos de tais movimentos, eles não deixam de confirmar a posição privilegiada ocupada pelo continente africano na estratégia de in- 
serção internacional desenvolvida pela política externa do governo Lula. $\mathrm{O}$ que, em consequência, impõe a necessidade de revisão de ações diplomáticas e comerciais brasileiras para a África, implicando a identificação e avaliação de canais eficazes na sua promoção e dimensionamento.

\section{Conclusão}

As relações Brasil-África ganharam novo impulso com o governo Lula, que passou a encarar de forma positiva as parcerias no âmbito das relações sul-sul. A cooperação com os países africanos passou a apresentar-se para o Brasil como elemento chave, capaz de transformar situaçōes e condições semelhantes, ainda que muitas vezes negativas, em oportunidades de cooperação e benefício mútuo. Ter consciência dessas possibilidades, bem como de seus riscos, torna-se essencial para a análise da política externa na medida em que sobre ela recai a responsabilidade de adotar as prioridades corretas para consecução dos projetos nacionais em plano externo.

Por esse prisma, duas ordens de fatores sobressaem ao se analisar as relações mantidas pelo Brasil com os países do continente africano ao longo do governo Lula: as relações políticas e as relaçōes comerciais, que atualmente ganham destaque nos projetos de cooperação na área energética (especialmente a exploração e prospecção de petróleo) e exportação de serviços de engenharia. Em relação à dimensão energética, é importante considerar que a exploração e a produção de petróleo transformaram-se num grande asset para o Brasil: num período inferior a duas décadas, o país passou de um importador maciço do produto a um dos maiores produtores mundiais fato constatado pela incessante busca de autossuficiência e, possivelmente, pela capacidade de ser um grande exportador no futuro próximo.

Para o continente africano, o petróleo, além do gás, também representa um triunfo econômico e tecnológico, cujas oportunidades de investimento têm atraído os grandes players internacionais, a exemplo de algumas empresas brasileiras, interessadas em participar tanto de projetos de engenharia do petróleo como daqueles voltados para a construção (ou reconstrução) de infraestrutura, mediante a exportação de serviços de engenharia. Os países africanos, em contrapartida, têm realizado esforços significativos para promoção de condições que favoreçam o ingresso desses investimentos: estabilidade das regras, previsibilidade no tratamento fiscal (comparativamente mais atraente do que no Brasil), processos seguros de licitação internacional de blocos de exploração e de efetiva capacidade de regulação. 
Nesse sentido, a definição e a constituição de canais efetivos de cooperação tornam-se essenciais para a promoção e consolidação das relações Brasil-África. Se os caminhos que se reabrem para a África no momento atual apontam para o reencontro de interesses político-comerciais promissores, torna-se imperativo identificar as motivações e as aspiraçōes, dos dois lados do Atlântico, capazes de promover canais efetivos de integração e adensamento das relações Brasil-África. Dessa perspectiva, uma análise da percepção tanto do setor empresarial como do corpo diplomático sobre a dinâmica político-comercial Brasil-África torna-se fundamental. Também se torna necessária uma análise individualizada dos produtos e serviços exportados pelo Brasil para esses países, bem como uma reflexão sobre as parcerias aí desenvolvidas por empresas brasileiras, na definição de um padrão que possa ser explorado e oferecido em outros países do continente.

Apesar de não ser possível determinar com precisão quais são os impactos de tais ajustes, é fato constatar que eles não deixam de confirmar a posição privilegiada ocupada pelo continente africano na estratégia de inserção internacional desenvolvida pela política externa brasileira. O que, em consequência, impõe a necessidade de revisão de ações diplomáticas e comerciais brasileiras para o continente africano, implicando a identificação e a avaliação de canais eficazes na sua promoção e dimensionamento. No processo de redefinição em que se inserem as relaçōes Brasil-África, África do Sul, Angola e Nigéria tornam-se vetores exemplares para a definição das estratégias diplomáticas e comerciais brasileiras em relação ao continente, fato que inspira estudos que possam contribuir como modelos de atuação dessa nova forma de pensar a agenda externa brasileira.

\section{Referências Bibliográficas}

Amorim, Celso Luiz Nunes. (2003), "O Brasil e o 'renascimento africano"'. Folha de S. Paulo, p. A3, 25/05.

. (2005), "Política externa do governo Lula: os dois primeiros anos". Análise de

Conjuntura OPSA, n. 4, mar.

CNI. (2006), Informa Notas Econômicas. Publicação da Confederação Nacional da Indústria. PEC/Unidade de Política Econômica, Brasília.

Lima, Maria Regina Soares de. (2003), "Na trilha de uma política externa afirmativa”.

Observatório da Cidadania. Rio de Janeiro, Ibase, pp. 94-100.

OCDE. (2006), “African Economic Outlook 2005/2006”. Disponível em <www.oecd.

org/bookshop>. 
OMC. (2007), The Annual Report of the World Trade Organization. 2007. Disponivel em <http://www.wto.org>.

Paulani, Leda Maria. (2003), "Brasil Delivery: razōes, contradições e limites da política econômica nos primeiros seis meses do governo Lula". Seminário "A Política Econômica do Novo Governo", promovido pelo Departamento de Economia da Universidade Federal do Espírito Santo, realizado em Vitória em 5 e 6 de junho de (mimeo.).

Prates, Daniela Magalhães \& Cunha, A. M. (2004), "Ajuste nas contas externas do Brasil: é o fim da vulnerabilidade?”. Anais do IX Encontro Nacional de Economia Política, Uberlândia, MG, v. 1.

SARAIVA, José Flávio Sombra. (1994), "Do silêncio à afirmação: as relações do Brasil com a África”. In: Cervo, A. L. (org.), O desafio internacional: a politica exterior do Brasil de 1930 a nossos dias. Brasília, Editora UnB. . (2004), "África e Brasil: o Fórum de Fortaleza e o relançamento da política africana do Brasil no governo Lula”. In: Coelho, Pedro Motta Pinto \& Saraiva, José Flávio Sombra (orgs.), Fórum Brasil-África: política, cooperação e comércio. Brasília, Ibri.

UnCTAD. (2005), Economic Development in Africa. Rethinking the Role of Foreign Direct Investment. UNCTAD/GDS/AFRICA. Disponível em <www.unctad.org>. 


\section{Resumo}

A política africana do governo Lula (2003-2006)

O artigo analisa as relações Brasil-África entre 2003 e 2006, procurando demonstrar que a eleição de Luiz Inácio Lula da Silva trouxe nova dinâmica às relaçōes do Brasil com o continente africano. O discurso e a prática diplomática deste governo convergem para a construção de alianças preferenciais com parceiros no âmbito das relações Sul-Sul. Nesse contexto, defende-se que África do Sul, Angola e Nigéria são parceiros políticos e econômicos essenciais à estratégia diplomática brasileira para o continente africano.

Palavras-chave: Brasil; África; Política externa; Relaçōes comerciais; Relações diplomáticas.

\section{Abstract}

The Lula government's African policy (2003-2006)

The article analyzes Brazil-Africa relations between 2003 and 2006, aiming to demonstrate that the election of Luiz Inácio Lula da Silva injected a new dynamic to Brazil's relations with the African continent. The discourse and diplomatic practice of the Lula government have combined to help build preferential alliances with partners within the arena of South-South relations. In this context the text argues that South Africa, Angola and Nigeria are essential political and economic partners in Brazil's diplomatic strategy for the African continent.

Keywords: Brazil; Africa; Foreign policy; Trade relations; Diplomatic relations.

Texto recebido em 30/1/ 2008 e aprovado em 15/8/ 2008.

Cláudio Oliveira Ribeiro é professor da Pontifícia Universidade Católica de São Paulo - PUC/SP e pesquisador no Núcleo de Estudos Legislativos e de Política Externa, da Universidade Federal de São Carlos, e no Núcleo de Pesquisa em Políticas Públicas da USP, onde desenvolve pós-doutorado. E-mail: professorclaudio@g mail.com. 